\title{
An expectancy model for memory search*
}

\author{
RICHARD M. SHIFFRIN and WALTER SCHNEIDER $\dagger$ \\ Indiana University, Bloomington, Indiana 47401
}

\begin{abstract}
A model for memory search is proposed in which $\mathrm{S}$ first forms an "expectancy" regarding the item to be tested on the next trial, then carries out a memory search. It is proposed that an expected item is encoded faster (or perhaps responded to more quickly), but the memory scanning process for expected and nonexpected items is otherwise identical. Assuming a serial exhaustive scanning process, we were able to fit much of the data in the literature. In addition, we tested the model by having $S$ give his expectancy aloud before each trial. The data showed about a $100-\mathrm{msec}$ advantage for expected items that did not interact with memory load. The model fit this data reasonably well.
\end{abstract}

Reaction time has long been used as a response measure to isolate and identify stages of information processing and retrieval (Donders, 1868). The use of this technique has increased markedly in recent years. In particular, Sternberg $(1966,1967,1969 \mathrm{a}, \mathrm{b})$ has used reaction time to illuminate the process of retrieval from short-term memory. In the basic paradigm, called "memory scanning," two sets of items are specified. An item is then presented and S gives as quickly as possible one of two responses indicating which set contains the presented item. In many cases, only one of the two sets of items is explicitly given to $\mathrm{S}$.

A large number of memory scanning studies have been carried out, and a number of scanning models have been proposed to account for various aspects of the data. In this paper we will review briefly the major empirical findings, evaluate the primary theories and their failings, propose a model to encompass the existing data, and present an empirical test of this model.

\section{TERMINOLOGY}

Our terminology roughly conforms to that used by Nickerson (1972).

\section{Stimulus Set}

The items from which the presented items will be chosen, e.g., the digits $0-9$, the letters of the alphabet, English words, etc. This is also called the target ensemble.

\section{Positive Set}

A subset of the stimulus set, normally no more than half as large as the stimulus set, which is small enough to be held in short-term memory. This subset always is explicitly described to the $S$. The $S$ gives one response if the presented item is in this set and another response if it is not. Many models propose that only this set is held in short-term memory. This is also called the memory set or the target set.

*This research was supported by PHS Grant 12717-05. tWe are indebted to Lloyd Peterson, who provided access to the computer on which the study was carried out.

\section{Positive Response}

The response given to a presented item in the positive set.

\section{Negative Set}

Those items in the stimulus set that are not in the positive set. This is also called the nontarget set.

\section{Negative Response}

The response given to a presented item in the negative set.

\section{Probe Set}

The item presented which is to be compared with the positive set stimuli. In a few experiments, more than one item makes up the probe set; in these cases the $S$ gives a positive response if any item in the probe set is also in the positive set.

\section{Varied Set Procedure}

In this procedure, a new positive set is given to the $S$ prior to each trial.

\section{Fixed Set Procedure}

The positive set remains fixed for a lengthy block of trials.

\section{Biased Stimulus}

A stimulus, usually of the positive set, which the $S$ is told or has learned is more likely to occur than any other stimulus.

\section{EMPIRICAL RESULTS}

In this section, we review only a few of the major results. Additional results will be discussed in conjunction with the various models. The basic results in scanning were published by Sternberg (1966). He used a stimulus set consisting of the 10 digits and used both varied and fixed set procedures. The results are shown as the squares in Figs. 1 and 2. These graphs give the mean reaction time (RT) as a function of positive set size for 


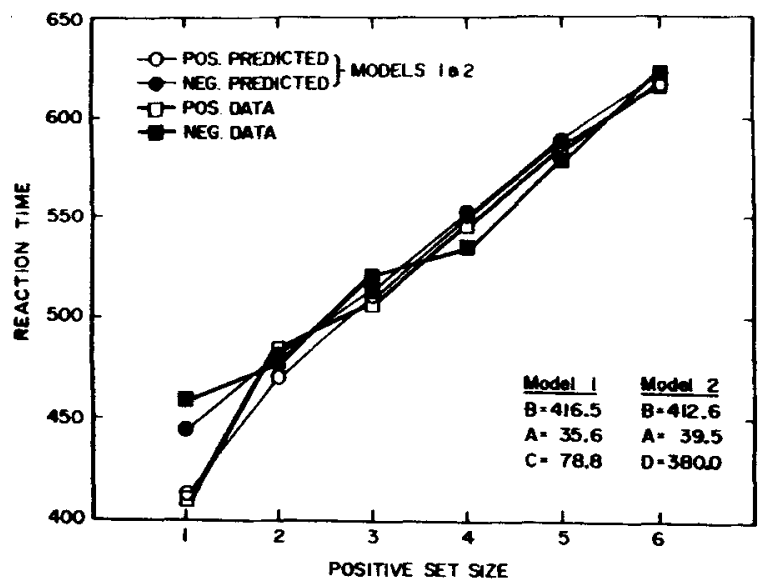

Fig. 1. Mean RT as a function of positive set size. Data (squares) from Sternberg (1966, Experiment 1). Predictions (circles) from Models 1 and 2 are indistinguishable.

both positive and negative responses. To a close approximation, these set-size functions exhibit two characteristics. First, the positive and negative functions are both linear. Second, the positive and negative functions are parallel. In these cases, the positive and negative functions tend to lie atop each other, but it is quite common for the negative function to be uniformly slower than the positive function. These curves may be characterized by their zero intercept, the point where the extended functions would cross the vertical axis if the display size were zero, and the slope, representing the additional time required to respond for each additional member of the positive set. These results are typical, showing a slope of about $38 \mathrm{msec}$.

Sternberg (1969a) has extended these results in a number of ways. If the probe item is degraded at presentation, then the intercept of the set-size curves is raised, but the curves are otherwise unaffected (at least for practiced Ss). When the stimulus set consisted of faces or forms rather than digits, the slope was increased but the linear parallel functions remained. In a fixed set procedure, a letter memory task was used in an attempt to eliminate the positive set from short-term store prior to target presentation. In this case, the intercept was raised and the slope approximately doubled, but the set-size functions were still parallel and linear. In another experiment using a varied set procedure, the task was altered so that the $S$ gave aloud the item in the positive set in the position following the position of the target item. In this experiment only positive targets were used. A linear set-size function was found with a slope of $124 \mathrm{msec}$.

We should note that some researchers have failed to find linear set-size functions and others have failed to find parallel positive and negative set-size functions. Most important are the findings that RT is a linear function of the $\log$ of the number of stimuli (Swanson \& Briggs, 1969; Briggs \& Swanson, 1970; Simpson, 1972). Simpson was able to produce log functions by giving Ss extensive recognition practice on the positive set and insuring that stimuli were always assigned to the positive set or the negative set, but never to both during the same experiment.

A number of studies using the fixed set procedure have shown that the relative frequency of presentation of probes from both the positive and negative sets will affect the RT: The higher is the presentation probability, the lower will be the RT. For example, Theios, Smith, Haviland, Traupmann, and Moy (1973) carried out a fixed set memory scanning experiment varying both positive set size and stimulus probability. These effects appeared to be additive. Theios (1973) reports a replication of the procedure of the Sternberg (1966) Experiment 2 in which stimulus probability was varied. Theios reported additive stimulus probability and memory set-size effects. Krueger (1970) used a positive set of four items and stimulus probabilities of $.5, .25$, and .125 . The RT for positive probes decreased linearly as stimulus probability increased. For negative items, the RT for probes with presentation probability of .5 was less than that for .25 and .125 probes (which were equal).

Another strong effect is that of serial position of members of the positive set on RT; this effect is seen in varied set memory scanning procedures. Although the effect can be large within a given experiment, the relationship between serial position and RT is inconsistent across experiments. Some studies find RT increases with serial position (Klatzky, Juola, \& Atkinson, 1971; Klatzky \& Smith, 1972); in other studies RT decreases with serial position (Corballis, 1967; Burrows \& Okada, 1971), and several have found no effect (Sternberg, 1969a; Clifton \& Birenbaum, 1970). Generally, the longer is the time interval between the presentation of the last positive set item and the probe stimulus, the less is the serial position effect

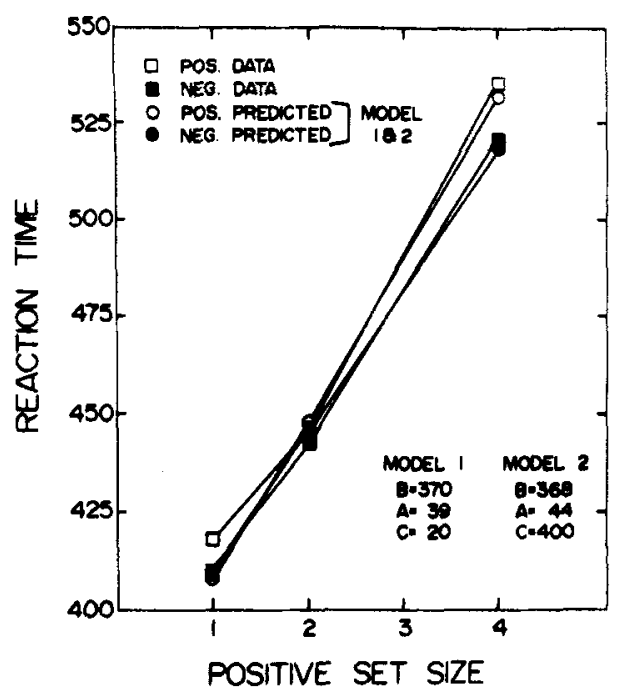

Fig. 2. Mean RT as a function of positive set size. Data (squares) from Sternberg (1966, Experiment 2). Predictions (circles) from Models 1 and 2 are indistinguishable. 
Fig. 3. Sternberg's (1969a, b) four-stage model of memory scanning.

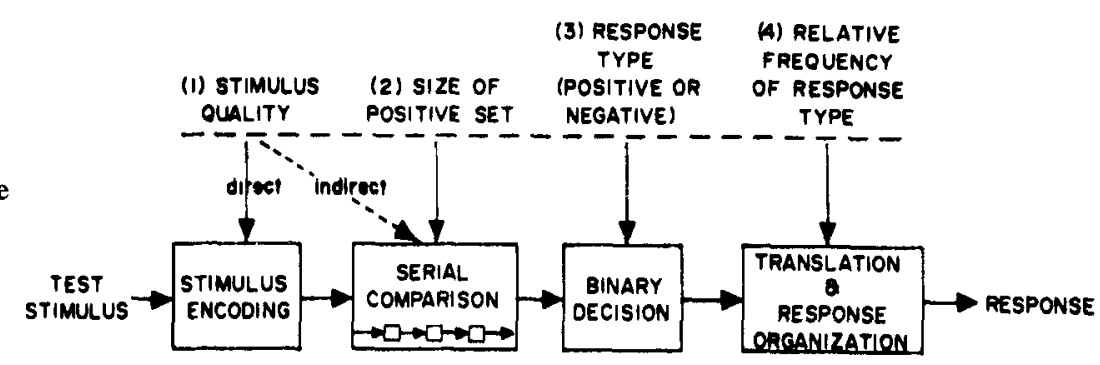

(Burrows \& Okada, 1971; Clifton \& Birenbaum, 1970; Corballis, 1967). When the time interval is greater than $2 \mathrm{sec}$, the effect seems to disappear (Corballis, 1967).

The final effect we would like to mention concerns probe and response repetitions from trial to trial. Peeke and Stone (1972) have shown that repetition of a probe from one trial to the next decreases RT but that response repetition without stimulus repetition leads to slower responses. Theios (1973) reports that both stimulus and response repetition reduce RT, with stimulus repetition much the stronger effect.

A number of related effects have occurred in paradigms somewhat different than those we have been discussing. These effects are found in choice RT experiments using a different response to each stimulus. First, RT is found to be linearly related to stimulus uncertainty (log of the number of stimuli, e.g., Hyman, 1953; Brainard, Irby, Fitts, \& Alluisi, 1962; Posner, 1964; Bernstein \& Reese, 1965; see also Hinrichs \& Craft, 1971). Second, stimulus repetition has been shown to be an important variable (Kornblum, 1973). Third, stimulus frequency has been shown to have strong effects on RT, with high frequency leading to fast responding (Smith, 1968).

Related to stimulus frequency effects and to sequential effects are effects based on expectancy. Bernstein and Reese (1965) showed that if the S verbally told the $\mathrm{E}$ before each trial the item he expected to occur on that trial, and if that item did occur, there was no effect of stimulus uncertainty and a fast RT resulted. Hinrichs and his coworkers have found that expectancy accounts for most of the stimulus probability effect (Hinrichs \& Krainz, 1970; Hinrichs, 1970; Hinrichs \& Craft, 1971).

\section{MODELS OF MEMORY SCANNING}

A fairly general model of scanning has been proposed by Sternberg $(1969 \mathrm{a}, \mathrm{b})$. The theory has four stages, diagrammed in Fig. 3. Stage 1, stimulus encoding, involves the transformation of sensory information into a stable form that can be operated on in memory. Stage 2, serial exhaustive comparison, is the process of comparing the probe stimulus with each member of the positive set in memory. Stage 3, response decision, consists of determining what response is appropriate, given the result of the serial comparison stage. Stage 4, response selection and evocation, is the process of selecting the program for the response and of executing the response.

While Sternberg's general model has four stages, the basic predictions dealt with in this paper result from the encoding and comparison stages. Equation 1 gives predictions of the model where the RT is equal to a base RT, B, plus the product of the scan time per element, A, times the positive-set size, $M$, plus the differential effect of encoding, $C$.

$$
\mathrm{RT}=\mathrm{B}+\mathrm{MA}+\mathrm{C}
$$

Obviously this model predicts linear set-size functions parallel for positive and negative targets. Degrading a stimulus has been shown (for practiced Ss) to increase the intercept but not the slope of memory scanning (Sternberg, 1967; Bracey, 1969), or, in terms of Eq. 1, to increase C. However, the Sternberg model does not directly account for stimulus probability or serial position effects. Sternberg has not suggested in print how these effects can be accounted for, but they presumably must be dealt with in the encoding or response stages. ${ }^{1}$

Murdock (1971) proposed a parallel processing model designed to deal explicitly with serial position effects. This model generates predictions based upon a parameter $\mathbf{b}$. Murdock assumed that $b$ varied from item to item, being a $\log$ function of recency and a linear function of primacy. Equation 2 expresses the formula for $b$, where $i$ is the position of the target in the positive set and $\alpha$ and $\beta$ are constants.

$$
\mathrm{b}=\beta(\mathrm{M}-\mathrm{i})+\alpha \ln (\mathrm{i})
$$

With the parameters Murdock estimated, the model predicts that RT will be highest at Serial Position 2. This was found in only 2 of the 13 studies reviewed earlier (see above). Other parameters could predict other results, but the author does not give a systematic or a priori procedure for parameter alteration. Furthermore, the model makes no predictions of stimulus probability or redundancy effects.

Burrows and Okada (1971) presented an alternative model designed to deal with serial position effects. This model is a slight modification of Sternberg's. It assumes that one of the items in memory can be in a special state. When this item is matched during scanning, the scan time for that item is reduced. Equations 3 and 4 


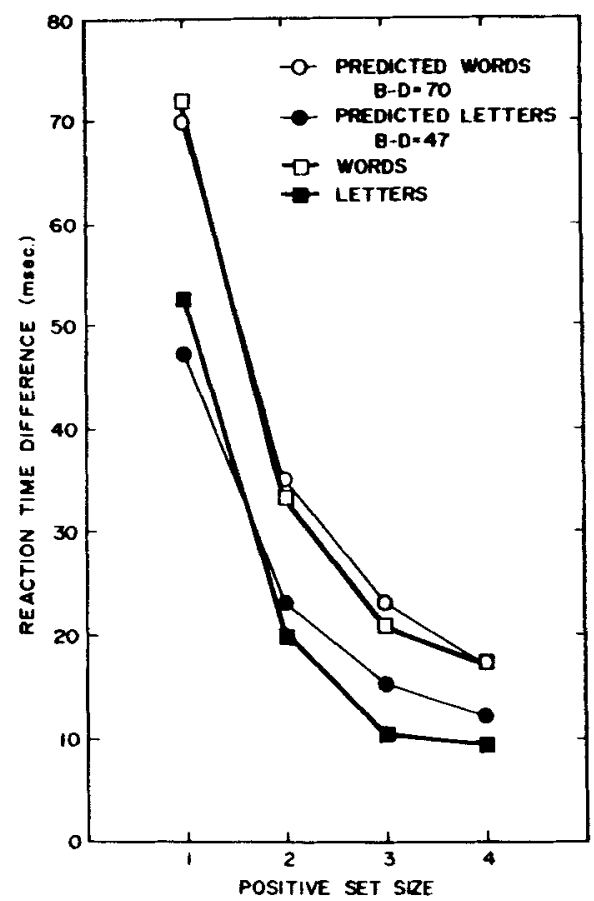

Fig. 4. Reaction time difference between positive and negative instances for naming the target as a function of positive set size. Data (squares) from Kirsner (1971). Predictions (circles) from a one-parameter expectancy model.

express the model where $P_{i}$ is the probability that the ith member is in the special state and $S$ is the saving in scan time when the item in the special state is scanned. The model predicted stimulus probability effects within the positive set.

$$
\begin{aligned}
\text { Positive Set RT } & =B+M A-S P_{i} \\
\text { Negative Set RT } & =B+M A
\end{aligned}
$$

There is a crucial problem with this model. The decrease in RT for a special state target is limited by the scan time per item. Estimates for special state scan time $(\mathrm{A}-\mathrm{S})$ from Burrows and Okada (1971) are .6 and $6.3 \mathrm{msec}$ (from the fast and slow intratrial delay conditions, respectively). But if this model is applied to predict the large stimulus bias effects of Burrows and Okada (1972), the estimate of A $-\mathrm{S}$ is $-120 \mathrm{msec}$. Such a finding is not sensible in the context of this model.

Theios et al (1973) presented a push-down stack scanning model. In this model both positive and negative memory set items are held in the stack and a scan consists of self-terminating search through the stack for an item and then making the response associated with it. If an item is not found in the stack, a parallel search through memory is made to find the response. In later versions of the model, the parallel and serial search occur simultaneously, with the response being made as soon as either terminates (Theios, 1973). Parameters of the model determine size of stack, movement of items within the stack, speed of scanning through the stack, and the rate of parallel search. If movement within the stack depends upon the frequency and serial position, then this model predicts frequency and serial position effects. These models were used to predict the set-size effects and the stimulus probability effects seen in Theios et al (1972).

There are two shortcomings to this theory. First, it lacks parsimony; it requires serial scanning through the stack, movement within the stack, parallel scanning through memory, and stack size varying with conditions. We think it would have difficulty accounting for the Sternberg (1966) Experiment 1 results. To predict an increase in negative set latencies as a function of positive set size, it is necessary to assume that negative items are almost always below the positive items in the stack (since the frequencies of negative and positive items were negatively correlated). However, this assumption will not easily predict parallel curves for negative and positive items.

\section{AN EXPECTANCY MODEL}

We propose a class of models in which the $\mathrm{S}$ expects one or more items to occur on each trial; if this item(s) is tested, the RT on that trial is reduced. Models of this type are supported by evidence from choice R'T experiments (see above) that expecting an item greatly reduces the S's RT. In the simplest case, suppose that the $\mathrm{S}$ chooses one item and "expects" this item to be tested as a target on the next trial. The choice of an item to expect will probably depend on factors like the frequency of occurrence of an item in fixed set procedures, serial input position in varied set procedures, and trial to trial repetitions in any procedure. Let us then assume that the $S$ responds more quickly when the expected item is indeed tested.

This basic expectancy model can be appended to almost any model of scanning. Since Sternberg's model is probably the most successful to date, we shall combine the expectancy model with Sternberg's scanning model and see how successfully the hybrid will handle the extant data. Certainly the hybrid should be able to deal with frequency, repetition, and serial position effects. But can it do so and still predict the parallel, linear data found by Sternberg and others?

Before turning to models for scanning, we would like to mention one result providing support for the expectancy hypothesis. Kirsner (1971) presented sets of items with set size $M=1,2,3,4$. With probability $.5, \mathrm{~S}$ was shown an item from this set (so a given item had test probability $.5 / \mathrm{M}$ ), and with probability $.5, \mathrm{~S}$ was shown an item not in the set for that trial. The S's task was to name aloud the test item. Kirsner found that the difference in RT between items in the presented set and items not in the presented set decreased as a function of $M$, the set size. Figure 4 shows the results. Also shown are the predictions from a model assuming that the $S$ expected one item from the presented set on each trial. 

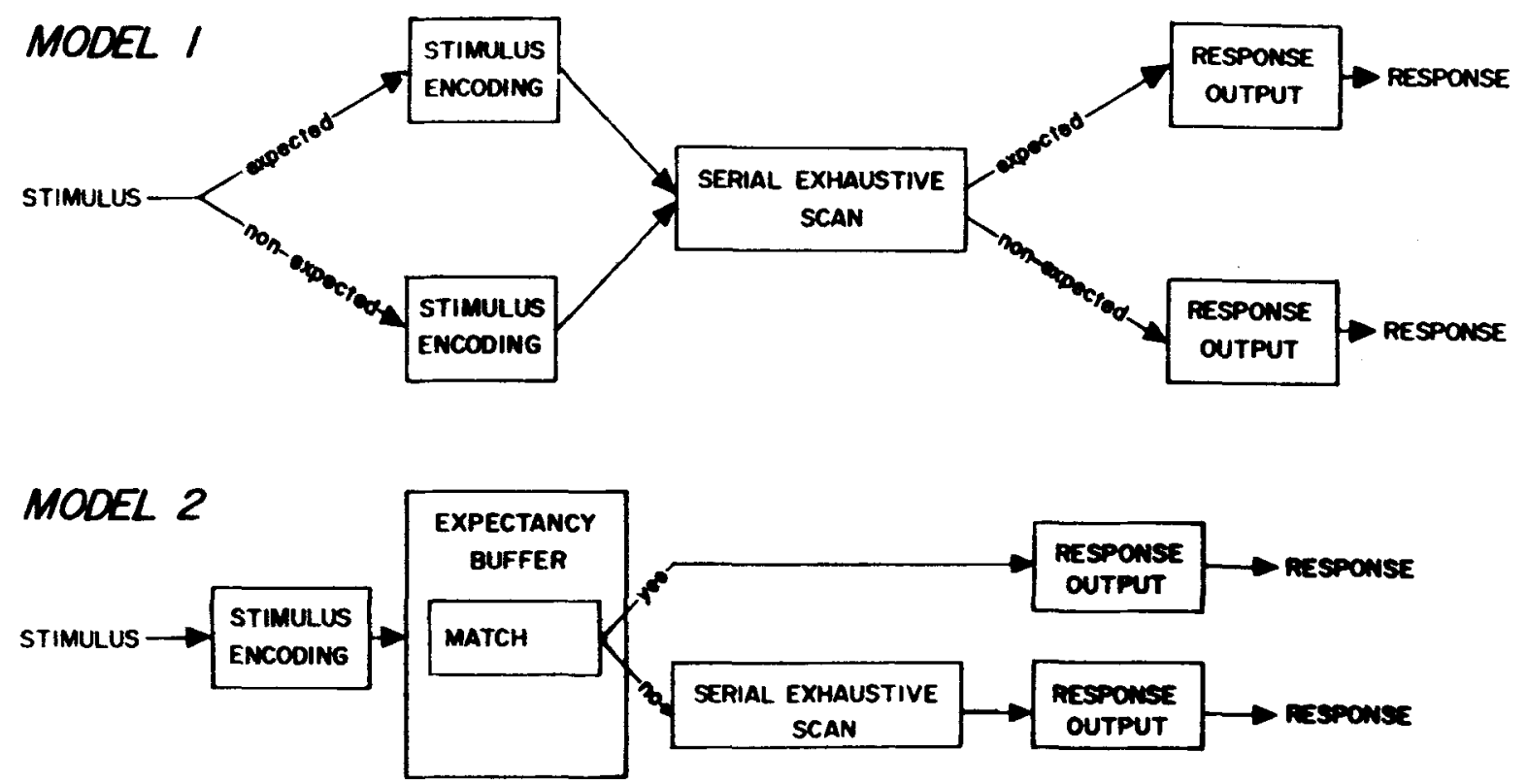

Fig. 5. Expectancy Models 1 and 2. Model 1 assumes expectancy affects perception or response times but does not affect scanning. Model 2 assumes correct expectancy causes an early termination of scanning.

(The selection is probably biased by serial position, but this does not affect the predictions.) The only parameter is $\mathrm{B}-\mathrm{D}$, the difference between fast and slow latencies. One experiment utilized words, another letters. Clearly, the predictions are quite good in both cases. ${ }^{2}$

To initiate our study of expectancy models for scanning, we will consider two very simple versions. In Model 1 the $\mathrm{S}$ always undertakes an exhaustive serial scan of the positive set, as proposed by Sternberg, but the latency will be $\mathrm{C}$ msec faster whenever the tested item is an expected item. In this model the source of the decrease in latency could lie either in the perceptual or the response stage (in terms of Sternberg's model). That is, one could perceive an expected item faster or could execute a response to an expected item faster. In any event, expectancy effects and scanning effects are independent in Model 1.

In Model 2 the $S$ first checks to see whether the target is expected; if so, he initiates a prepared response at once; if not, he carries out an exhaustive serial scan through the members of the positive set (including the expected item) and then responds. Expectancy and scanning effects are dependent in Model 2. These models are illustrated in Fig. 5.

For either model, we must specify the basis for the S's expectancy. We assume for fixed set procedures that the $S$ will expect item i (from positive or negative sets) with a probability equal to the relative frequency of occurrence of item $i$. The probability matching rule can arise from many models. For example, suppose that the $S$ has a buffer of size 1 containing the expected item. On each trial the target will enter the buffer (and replace the current expected item) with probability $\gamma$. This model predicts probability matching independent of the value of $\gamma$ (but $\gamma$ will determine the extent of stimulus repetition effects).

The predictions of the models are straightforward. Let $\mathrm{A}$ be the scanning time per item scanned. Let $\mathrm{B}$ be the base RT. Let M be the size of the positive set. Let $\alpha_{i}$ be the relative frequency of the tested item (which in some experiments varies with memory set size). For Model 1, let $\mathrm{C}$ be the decrease in latency when an expected itom is tested. For Model 2, let D be the total RT when an expected item is tested. For each model we can then write the equations giving the RT for expected items, for nonexpected items, for items with unknown expectancy (but known frequency), and for tests of an item with unknown expectancy and frequency (which will be the overall mean RT, dependent only on positive set size). The predictions are given in Eqs 5-12.

$$
\begin{aligned}
& \text { Model } 1 \\
& \text { Expected: } \mathrm{RT}=\mathrm{B}+\mathrm{MA}-\mathrm{C} \\
& \text { Nonexpected: } \mathrm{RT}=\mathrm{B}+\mathrm{MA} \\
& \text { Unknown Expectancy: RT }=(B+M A)\left(1-\alpha_{i}\right)+(B+M A-C) \alpha_{i}=B+M A-C\left(\alpha_{i}\right) \\
& \text { Unknown Expectancy and Frequency: RT }=\sum_{i} \alpha_{i}\left(B+M A-C \alpha_{i}\right) \\
& \text { Model } 2 \\
& \text { Expected: } \mathrm{RT}=\mathrm{D} \\
& \text { Nonexpected: } \mathrm{RT}=\mathrm{B}+\mathrm{MA} \\
& \text { Unknown Expectancy: } \mathrm{RT}=\alpha_{\mathrm{i}}(\mathrm{D})+\left(1-\alpha_{\mathrm{i}}\right)(\mathrm{B}+\mathrm{MA}) \\
& \text { Unknown Expectancy and Frequency: } R T=\sum_{i} \alpha_{i}\left[\alpha_{i} D+\left(1-\alpha_{i}\right)(B+M A)\right]
\end{aligned}
$$




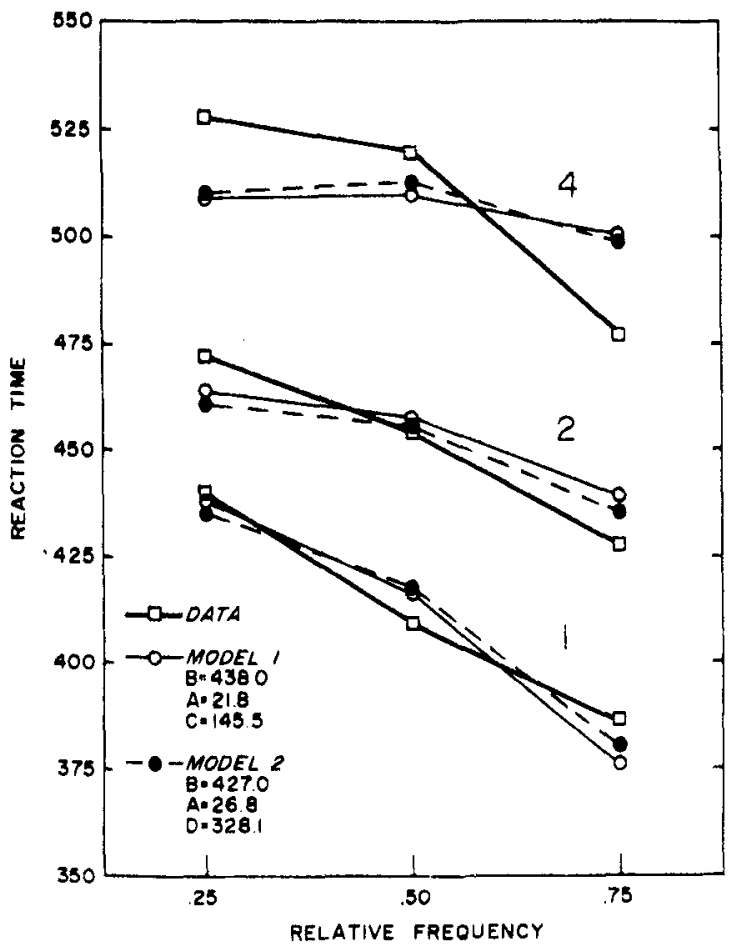

Fig. 6. Mean RT as a function of response frequency. Data (squares) from Sternberg (1969b, Experiment 4). Predictions (circles) from Models 1 and 2.

Note that the summation in Eqs. 8 and 12 is to be taken over the frequency of members of the positive or negative sets, depending on which prediction is desired. In some experiments the RT for negative set stimuli appears to differ from the RT to positive set stimuli by a constant amount. Thus, we will propose an additional parameter, E, representing the constant difference between negative and positive targets. In other words, for each of Eqs. 5-12 we will add a constant $E$ for negative set stimuli. In most cases, $\mathrm{E}$ was estimated essentially equal to zero. In the cases where $E$ was not estimated equal to zero, we report the values.
We should note that only in special cases do these models predict linear set-size functions. Nevertheless, these models may be good predictors of the data, as long as the predicted deviations from linearity are not unduly large. To test these models, we fit each of them to a variety of extant data in the literature. In each case, the three or four parameters of the models were chosen so as to minimize the sum of squared deviations of the predictions from the data. Appendix 1 gives the minimum sum of squares for each set of data we have fit.

Figure 1 shows the data and predictions for Sternberg's 1966 Experiment 1, which utilized a varied set procedure. Equations 8 and 12 were used to derive predictions for the two models. We assumed that the $\mathrm{S}$ expected an item in the positive set with $\alpha_{i}=.5 / \mathrm{M}$ and an item in the negative set with $\alpha_{\mathrm{i}}=.5 /(10-\mathrm{M})$, which were the stimulus probabilities. The predictions were not discriminably different for the two models.

Figure 2 shows the data and predictions for Sternberg's 1966 Experiment 2, which utilized a fixed set procedure. In this case, $\alpha_{i}$ values were calculated from the stimulus probabilities as given in the article; Eqs. 8 and 12 were then used to derive predictions.

Figure 6 shows the data and predictions for Sternberg's Experiment 4 (1969a), which varied both stimulus and response probability by varying the probability of the positive set as a whole. If the frequency of the positive set was $f$, then $\alpha_{\mathrm{i}}$ was set equal to $\mathrm{f} / \mathrm{M}$. Then Eqs. 8 and 12 were used to derive predictions. Note that the predictions are based only on the effects of stimulus frequency, not response frequency (but we do not mean to imply by this that response frequency does not, in general, affect RT).

Table 1 shows the data and predictions for Theios et al (1973), which varied stimulus probability while holding response probability constant (except for $M=1)$. Equations 7 and 11 were used to derive predictions. The fit was as good as that for Theios's model and our model predicts the set-size 1 point, which

Table 1

Mean Reaction Time (Milliseconds) from Theios et al (1973)

Predictions from Model 1: $\mathrm{B}=\mathbf{5 2 3}, \mathrm{A}=\mathbf{2 1 . 5}, \mathrm{C}=\mathbf{2 1 6 . 7 ,} \mathrm{E}=31 \quad$ Predictions from Model 2: $\mathrm{B}=483, \mathrm{~A}=32.3, \mathrm{D}=384, \mathrm{E}=26.4$

\begin{tabular}{|c|c|c|c|c|c|c|c|c|}
\hline \multirow{2}{*}{$\begin{array}{l}\text { Set } \\
\text { Size }\end{array}$} & \multicolumn{4}{|c|}{ Positive Target Set } & \multicolumn{4}{|c|}{ Negative Nontarget Set } \\
\hline & $\mathrm{p}$ & Data & Model 1 & Model 2 & $\mathrm{p}$ & Data & Model 1 & Model 2 \\
\hline 1 & .15 & 483 & 511 & 495 & .85 & 407 & 391 & 430 \\
\hline 2 & $\begin{array}{l}.35 \\
.15\end{array}$ & $\begin{array}{l}498 \\
543\end{array}$ & $\begin{array}{l}490 \\
533\end{array}$ & $\begin{array}{l}490 \\
523\end{array}$ & $\begin{array}{l}.35 \\
.15\end{array}$ & $\begin{array}{l}519 \\
550\end{array}$ & $\begin{array}{l}521 \\
564\end{array}$ & $\begin{array}{l}517 \\
549\end{array}$ \\
\hline 3 & $\begin{array}{l}.30 \\
.15 \\
.05\end{array}$ & $\begin{array}{l}522 \\
549 \\
604\end{array}$ & $\begin{array}{l}522 \\
554 \\
576\end{array}$ & $\begin{array}{l}521 \\
551 \\
570\end{array}$ & $\begin{array}{l}.30 \\
.15 \\
.05\end{array}$ & $\begin{array}{l}546 \\
510 \\
634\end{array}$ & $\begin{array}{l}503 \\
586 \\
607\end{array}$ & $\begin{array}{l}548 \\
577 \\
597\end{array}$ \\
\hline 4 & $\begin{array}{l}.20 \\
.15 \\
.10 \\
.05\end{array}$ & $\begin{array}{l}546 \\
576 \\
597 \\
609\end{array}$ & $\begin{array}{l}565 \\
576 \\
587 \\
598\end{array}$ & $\begin{array}{l}567 \\
578 \\
589 \\
601\end{array}$ & $\begin{array}{l}.20 \\
.15 \\
.10 \\
.05\end{array}$ & $\begin{array}{l}589 \\
612 \\
628 \\
626\end{array}$ & $\begin{array}{l}596 \\
607 \\
618 \\
629\end{array}$ & $\begin{array}{l}593 \\
605 \\
616 \\
627\end{array}$ \\
\hline 5 & $\begin{array}{l}.20 \\
.15 \\
.05 \\
\end{array}$ & $\begin{array}{l}578 \\
587 \\
630\end{array}$ & $\begin{array}{l}587 \\
598 \\
619\end{array}$ & $\begin{array}{l}593 \\
606 \\
632 \\
\end{array}$ & $\begin{array}{l}.20 \\
.15 \\
.05\end{array}$ & $\begin{array}{l}611 \\
624 \\
658\end{array}$ & $\begin{array}{l}618 \\
629 \\
650\end{array}$ & $\begin{array}{l}619 \\
632 \\
658\end{array}$ \\
\hline
\end{tabular}


Theios's model did not predict.

Figure 7 shows the data and predictions for Theios (1973), which replicated the procedure of Sternberg's Experiment 2 (1966), and breaks down the data for each stimulus probability as well as memory set size. (Note that Theios found an effect of item frequency within the negative set which Sternberg did not find.) Equations 7 and 11 were used to fit these data.

Figure 8 shows the data and predictions for Klatzky and Smith (1972) which biased S to expect a particular item by putting one or two stars above that item when the varied set was presented. Two stars implied that the starred item would be tested with probability .8 , given that a positive set item was tested. One star was similar, except that the probability was .4. On control trials (termed "mixed") no stars were presented. The probability of the positive set was always .6. To fit this data, we assumed that the $S$ always expected the starred item and, if there were no stars, expected one of the positive set with probability $1 / \mathrm{M} .^{3}$ Equations 5 and 6,9 and 10 were used to fit the results. Note that Model 2 appears not to predict the curve for the positive set biased items. Model 1 fits the data reasonably well (although the predicted linearity of the positive set size functions does not hold in this case).

Figure 9 shows the data and predictions from Burrows

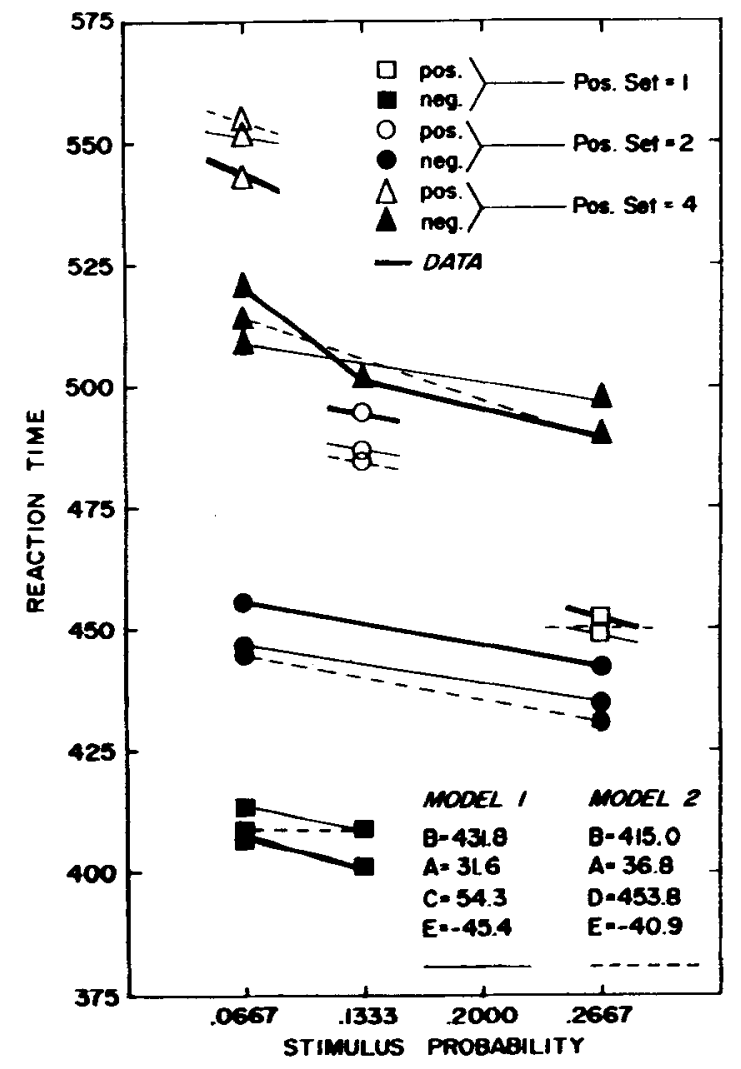

Fig. 7. Mean RT as a function of stimulus probability and positive set size. Data (heavy lines) from Theios (1973). Predictions (light lines) from Models 1 and 2.

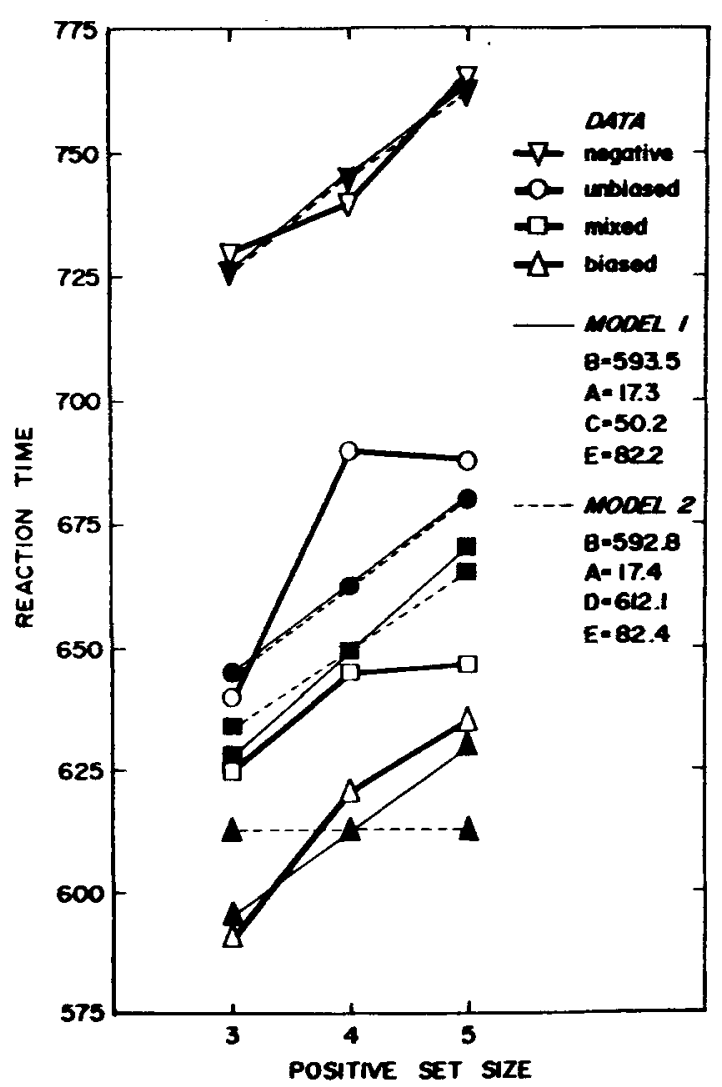

Fig. 8. Mean RT as a function of positive set size and degree of bias. Data (heavy lines) from Klatzky and Smith (1972). Predictions (light lines) from Models 1 and 2.

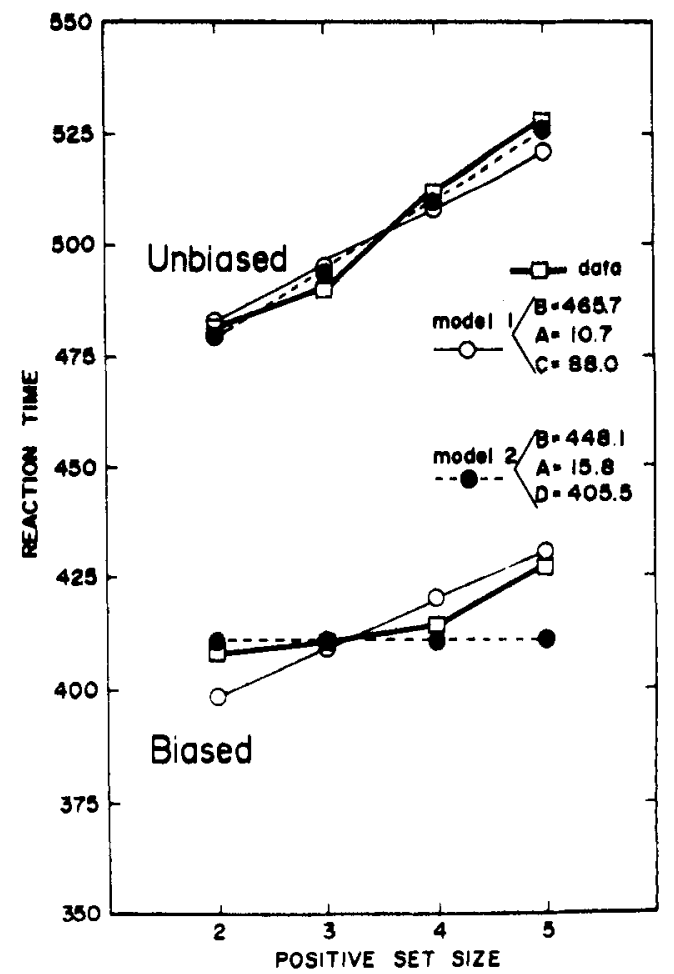

Fig. 9. Mean RT as a function of positive set size and degree of bias. Data (squares) from Burrows and Okada (1972). Predictions (circles) from Models 1 and 2. 

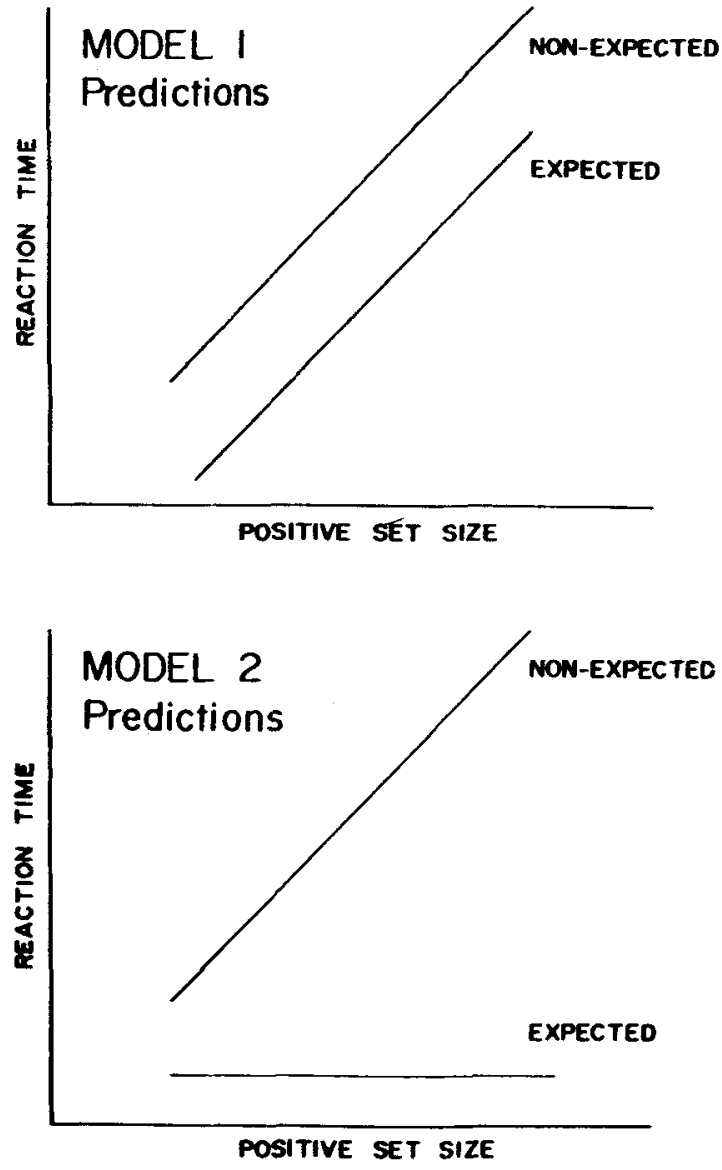

Fig. 10. Predictions for set-size functions for (correctly) expected and (incorrectly) nonexpected targets. Model 1 (top) predicts no interaction of set size and expectancy. Model 2 (bottom) predicts a strong interaction: a flat line for expected items.

and Okada (1972). They utilized a fixed set procedure. The probability of the positive set was always .5. For an entire block of trials using a given positive set size, the first member of the positive set was tested on $60 \%$ of the positive set trials. Extensive training was used, so that the $\mathrm{S}$ may be presumed to have learned that this was always the case and to expect the first item (termed "biased"). Again, Equations 5 and 6,9 and 10 were used to derive predictions.

These figures show that either of two expectancy models based on Sternberg's basic scanning theory can handle much of the data very well, including frequency effects. There are other data, especially the data exhibiting marked deviations from linearity, that cannot be well handled either by Sternberg's model or by our expectancy version. It may be that the hypothesis of exhaustive serial scanning does not accurately represent scanning in such situations. Note, however, that frequency and serial position effects are seen in these experiments also and that it could well be necessary to append an expectancy hypothesis to whatever scanning model is needed.

It appears from an appraisal of the figures that the current data (with the possible exception of Klatzky \& Smith, 1972) do not provide a means for distinguishing the two proposed models. Furthermore, although the predictions are good, support for the expectancy hypothesis is only indirect. We therefore carried out an experiment to test the expectancy model and to distinguish between the two versions in question. The paradigm utilized the straightforward procedure of asking Ss to predict before each trial which stimulus they expect as a probe on the next trial. The memory set size predictions for the models, for expected and nonexpected stimuli, are shown in Fig. 10. There is a clear difference in the predictions.

\section{METHOD}

Subjects

Ss were three male and two female right-handed students aged 18-22 years who were paid $\$ 2-\$ 2.50$ per each of six 1 -h sessions. Three Ss responded to the positive set with their right hand, two with their left.

\section{Apparatus}

The experiment was run on a PDP-8 Digital Equipment Corporation computer. The stimuli were presented on an IEE 90 binaview tube $30 \mathrm{in}$. from the $\mathrm{S}$. The $\mathrm{S}$ responded by pressing one of two telegraph keys with the forefinger of each hand.

\section{Procedure}

The stimuli consisted of the numbers 2-9. A fixed set procedure was used. The stimuli for each block of trials were randomly chosen, with the constraint that the positive set or negative set numbers could not be consecutive. $\mathrm{S}$ was presented before each block of trials a card on which was printed the positive set (but not the negative set) stimuli. The stimuli were permuted within each group of 20 trials, so that the stimuli had the relative frequencies shown in Table 2 . The positive set size was equal to the negative set $\operatorname{size}^{4}$ and took on values $M=1,2$, 3 , and 4. A trial sequence is depicted in Fig. 11. First an X was presented on the binaview for $1-10 \mathrm{sec}$. During this time, $S$ was instructed to predict verbally which digit he expected to appear on that trial. Upon hearing $S$ begin to say the digit, E pushed a button. This caused the $X$ to be removed about $1.5 \mathrm{sec}$ after the $\mathrm{S}$ started saying the prediction. After the $\mathrm{X}$ was removed, the binaview was blank for $.5 \mathrm{sec}$, then the target digit was presented. The target remained until $S$ pressed one of the two keys or $2 \mathrm{sec}$ had elapsed. Thereafter, the binaview went blank for $1 \mathrm{sec}$ and the next trial began.

A block consisted of 160 trials, during which the set size and positive and negative stimuli were fixed. Each day $S$ received two blocks. Midway in each block there was a forced rest of $10 \mathrm{sec}$. Between blocks there was a rest of $3 \mathrm{~min}$.

The conditions were permuted randomly so that each $S$ received exactly one of each of the four positive set sizes in each consecutive series of four blocks. The Ss were informed each day

Table 2

Conditions for Expectancy Experiment: Stimulus Presentation Probabilities

\begin{tabular}{|c|c|c|c|c|c|c|c|c|}
\hline \multirow{2}{*}{$\begin{array}{l}\text { Memory } \\
\text { Set Size }\end{array}$} & \multicolumn{4}{|c|}{ Positive Set Stimuli } & \multicolumn{4}{|c|}{ Negative Set Stimuli } \\
\hline & $s_{1}$ & $\mathrm{~s}_{2}$ & $\mathrm{~s}_{3}$ & $s_{4}$ & $s_{s}$ & $s_{6}$ & $s_{7}$ & $s_{8}$ \\
\hline 1 & .20 & & & & .80 & & & \\
\hline 2 & .30 & .20 & & & .30 & .20 & & \\
\hline 3 & .25 & .20 & .05 & & .25 & .20 & .05 & \\
\hline 4 & .20 & .15 & .10 & .05 & .20 & .15 & .10 & .05 \\
\hline
\end{tabular}


TRIAL FORMAT

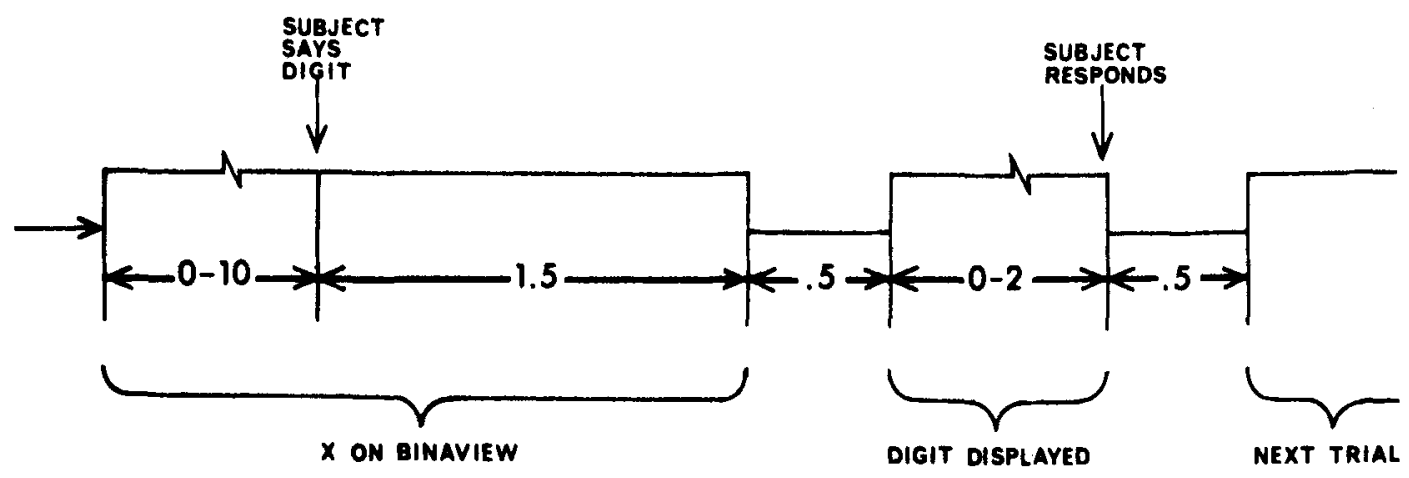

TIME (SEC.)

Fig. 11. Trial sequence for the expectancy experiment. The timing for a single trial is depicted.

of their average RT and error rate. They were encouraged to keep their average time less than $.5 \mathrm{sec}$ and to keep their error rate less than $5 \%$. Ss who succeeded in meeting these standards for a block were paid $\$ 1.25$; other Ss were paid $\$ 1 .^{5}$

\section{RESULTS}

The first 40 trials of each block were considered practice and were not included in the analysis. Error rates for Memory Set Sizes 1, 2, 3, and 4 were,

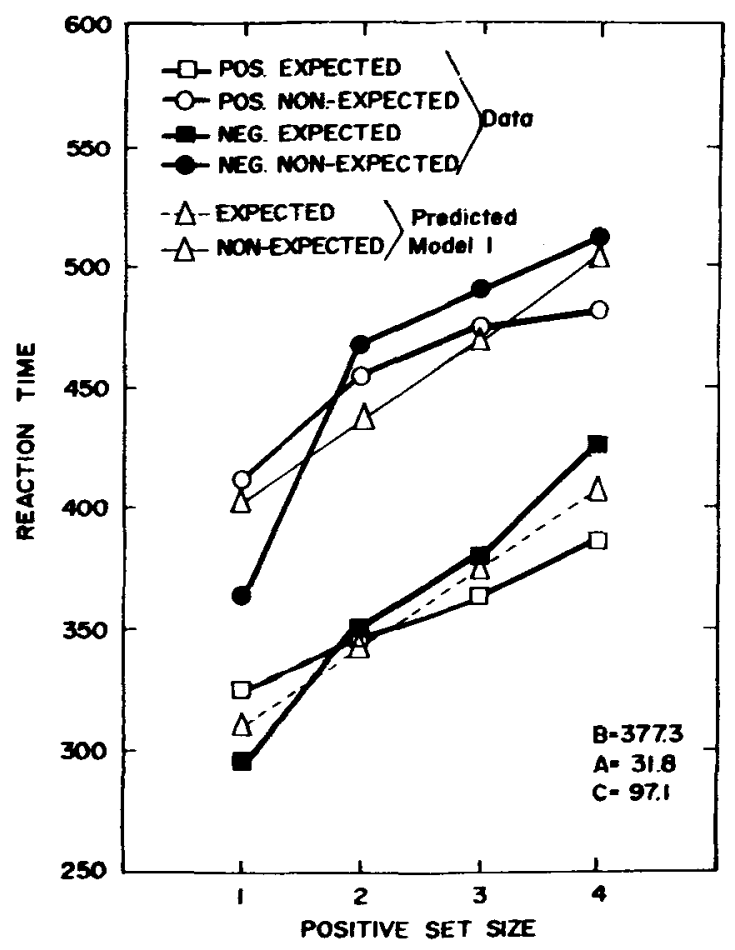

Fig. 12. Mean RT as a function of positive set size and expectancy. Predictions from Model 1 only, since Model 2 clearly mispredicts the "expected" function. respectively, $2.6 \%, 3.7 \%, 4.8 \%$, and $4.5 \%$. All data to follow is based upon mean RTs for correct responses; medians were also examined but were not qualitatively different from means.

Figure 12 shows the set-size effects for expected and nonexpected items. The set-size effects, expectancy effects, and response effects were significant by an $F$ test $[F(3,4773)=582, p<.001 ; F(1,4773)=814, p<.001 ;$ $F(1,4773)=15, p<.001]$.

The interactions between expectancy and set size and between set size and response were significant $[F(3,4773)=6.7, p<.001 ; F(3,4773)=50, p<.01]$. The interaction of response and expectancy and of response, set size, and expectancy were not significant $[F(1,4773)=2.84, \quad p<.092 ; \quad F(3,4773)=2.67$, $\mathrm{p}<.046]$. The interaction between expectancy and set size was due to Set Size 1. When analyzed for Set Sizes $2-4$, the effect was nonsignificant $[F(2,3623)=2.34$, $\mathrm{p}<.097]$. The RT for expected items increased linearly with set size. The set-size functions for nonexpected items were not linear. Averaging across conditions, the slope of the set-size function was $31.8 \mathrm{msec}$. Table 3 gives the slope values for each curve, both including and excluding the point $\mathrm{M}=1$.

Stimulus probability effects are presented in Table 4. In summary, there were minimal stimulus frequency

Table 3

Slopes for Reaction Time (in Milliseconds) Set-Size Functions

\begin{tabular}{lcc} 
& Positive & Negative \\
\hline \multicolumn{3}{c}{ Slopes Based on All Set Sizes } \\
Expected & 17.7 & 41.7 \\
Nonexpected & 22.3 & 45.7 \\
Slopes Based on All Set Sizes Excluding & $\mathrm{M}=1$ \\
Expected & 18.5 & 38.0 \\
Nonexpected & 12.5 & 21.5 \\
\hline
\end{tabular}


Table 4

A. Mean Reaction Time (Milliseconds) for Expected Stimuli Predictions from Model 1: $\mathrm{B}=377.3, \mathrm{~A}=31.8, \mathrm{C}=97.1$

\begin{tabular}{|c|c|c|c|c|c|c|c|c|}
\hline \multirow{2}{*}{$\begin{array}{l}\text { Set } \\
\text { Size }\end{array}$} & \multicolumn{4}{|c|}{ Positive Target Set } & \multicolumn{4}{|c|}{ Negative Target Set } \\
\hline & $\mathrm{p}$ & Data & Predictions & SD & $\mathrm{p}$ & Data & Predictions & SD \\
\hline 1 & .2 & 331 & 312 & 61 & .8 & 297 & 312 & 69 \\
\hline 2 & $\begin{array}{l}.3 \\
.2\end{array}$ & $\begin{array}{l}346 \\
352\end{array}$ & $\begin{array}{l}344 \\
344\end{array}$ & $\begin{array}{l}69 \\
90\end{array}$ & $\begin{array}{l}.3 \\
.2\end{array}$ & $\begin{array}{l}347 \\
357\end{array}$ & $\begin{array}{l}344 \\
344\end{array}$ & $\begin{array}{l}54 \\
68\end{array}$ \\
\hline 3 & $\begin{array}{l}.25 \\
.20 \\
.05\end{array}$ & $\begin{array}{l}359 \\
368 \\
369\end{array}$ & $\begin{array}{l}375 \\
375 \\
375\end{array}$ & $\begin{array}{l}75 \\
83 \\
63\end{array}$ & $\begin{array}{l}.25 \\
.20 \\
.05\end{array}$ & $\begin{array}{l}358 \\
407 \\
344\end{array}$ & $\begin{array}{l}375 \\
375 \\
375\end{array}$ & $\begin{array}{l}80 \\
92 \\
72\end{array}$ \\
\hline \multirow[t]{2}{*}{4} & $\begin{array}{l}.20 \\
.15 \\
.10 \\
.05\end{array}$ & $\begin{array}{l}383 \\
370 \\
398 \\
402\end{array}$ & $\begin{array}{l}407 \\
407 \\
407 \\
407\end{array}$ & $\begin{array}{l}70 \\
59 \\
90 \\
73\end{array}$ & $\begin{array}{l}.20 \\
.15 \\
.10 \\
.05\end{array}$ & $\begin{array}{l}414 \\
433 \\
434 \\
386\end{array}$ & $\begin{array}{l}407 \\
407 \\
407 \\
407\end{array}$ & $\begin{array}{r}92 \\
97 \\
65 \\
128\end{array}$ \\
\hline & & B. Mean I & Reaction Time & (Milliseconds) for & Nonexpected & Stimuli & & \\
\hline 1 & .2 & 411 & 409 & 89 & .8 & 366 & 409 & 71 \\
\hline 2 & $\begin{array}{l}.3 \\
.2\end{array}$ & $\begin{array}{l}451 \\
462\end{array}$ & $\begin{array}{l}441 \\
441\end{array}$ & $\begin{array}{r}110 \\
86\end{array}$ & $\begin{array}{l}.3 \\
.2\end{array}$ & $\begin{array}{l}458 \\
483\end{array}$ & $\begin{array}{l}441 \\
441\end{array}$ & $\begin{array}{r}90 \\
102\end{array}$ \\
\hline 3 & $\begin{array}{l}.25 \\
.20 \\
.05\end{array}$ & $\begin{array}{l}466 \\
492 \\
538\end{array}$ & $\begin{array}{l}473 \\
473 \\
473\end{array}$ & $\begin{array}{r}79 \\
113 \\
149\end{array}$ & $\begin{array}{l}.25 \\
.20 \\
.05\end{array}$ & $\begin{array}{l}478 \\
497 \\
531\end{array}$ & $\begin{array}{l}473 \\
473 \\
473\end{array}$ & $\begin{array}{r}94 \\
105 \\
125\end{array}$ \\
\hline 4 & $\begin{array}{l}.20 \\
.15 \\
.10 \\
.05\end{array}$ & $\begin{array}{l}467 \\
480 \\
494 \\
518\end{array}$ & $\begin{array}{l}504 \\
504 \\
504 \\
504\end{array}$ & $\begin{array}{r}110 \\
108 \\
98 \\
110\end{array}$ & $\begin{array}{l}.20 \\
.15 \\
.10 \\
.05\end{array}$ & $\begin{array}{l}493 \\
503 \\
530 \\
569\end{array}$ & $\begin{array}{l}504 \\
504 \\
504 \\
504\end{array}$ & $\begin{array}{r}97 \\
109 \\
137 \\
140\end{array}$ \\
\hline
\end{tabular}

effects for expected items. For nonexpected items, Set Sizes 2-4, there were significant effects of frequency $[F(1,754)=6.01, p<.014 ; F(2,991)=23.9, p<.001$; $F(3,1163)=12.5, \mathrm{p}<.001]$.

Figure 13 shows the probability of expecting an item as a function of its presentation probability. There is a bias toward expecting positive set items. The data show a moderate approximation to probability matching if they are collapsed over positive and negative sets:

There was no response bias induced by the response appropriate for the expected item. The RT for a nonexpected item that was in the same response class as the expected item was $476 \mathrm{msec}$. The RT for a nonexpected item that was in the opposite response class to the expected item was $485 \mathrm{msec}$. These RTs are means over Positive Set Sizes 2, 3, and 4. These were not significantly different, as indicated by an analysis of the interaction of response class and positive set size $[\mathrm{F}(1,2911)=1.59, \mathrm{p}<.208]$.

\section{DISCUSSION}

The results show that expecting an item can greatly decrease RT to that item. Responses to expected items

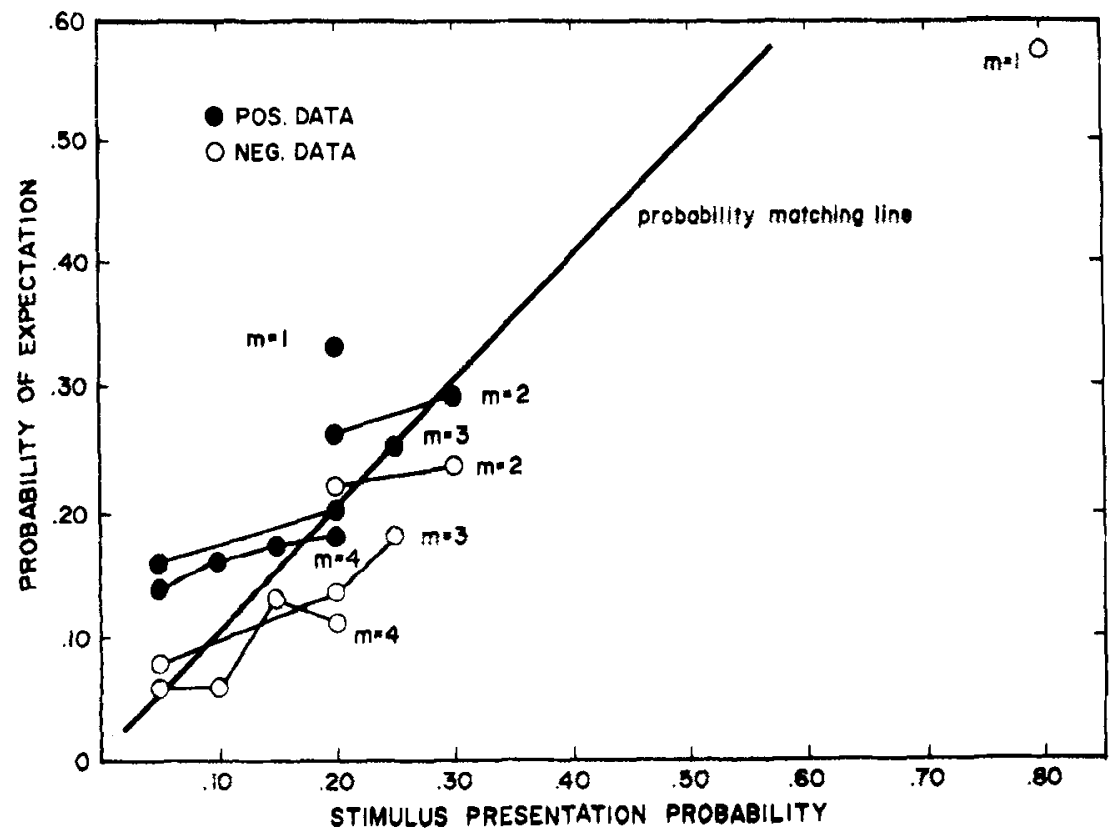

Fig. 13. Probability of "expecting" an item as a function of its stimulus presentation probability. 
were about $100 \mathrm{msec}$ faster than responses to nonexpected items. That amounts to about $20 \%$ of the total RT for Memory Set 4 and about three times the amount of time it took to compare an element in memory (as measured by the slope of the memory set size function).

Model 1 with only three parameters predicts some of the effects shown in the data (Fig. 12, Table 3). The large expectancy effect, the lack of stimulus probability effects on expected items, and the independence of set size and expectancy were well predicted.

Model 2 did not fit the memory set size functions and, hence, can be ruled out of consideration for the present experiment. We should like to point out, however, that Model 2 could very well apply in other experimental situations; the choice of scanning strategy might vary with conditions and instructions. For example, we would expect Model 2 to apply if we gave a high payoff for a fast response to the S's expected item, but no payoffs otherwise. Finally, it is possible that both models could apply in the same experiment; an expected item could get an advantage for two independent reasons: (1) a decrease in perception or response time or (2) scan bypass when the expected item is matched. Further research will be necessary to explore these possibilities.

Although Model 1 fits certain aspects of the data, there are a number of features which Model 1 does not predict. First, the set-size functions are not quite linear. The major deviation, however, results from the negative set size of 1 condition. This is the only condition in which response probability was not equalized for negative and positive responses; the negative response occurred $80 \%$ of the time. Hence, a response bias could account for the very fast RTs at this point.

Second, the effect of the stimulus probability on nonexpected items was not predicted. Both Models 1 and 2 predict that there should be no effect of stimulus probability on RT for expected and nonexpected items taken separately. ${ }^{6}$ The observed stimulus probability effect for the nonexpected items may be due in part to difficulties in experimental control. If the $\mathrm{S}$ switches his expectancy to a new item after his verbal report and before the test, the RT distributions will be a partial mixture of expected and nonexpected RTs and show some stimulus probability effects. If we assume the $\mathrm{S}$ switched his expectancy with probability $\epsilon$ and resampled at random among the remaining items for a new expected item, the model can predict most of the stimulus probability effects except for the point $M=3$, $\alpha=.05$. However, the model requires a large value for the parameter $\mathrm{C}$ to fit the results. Another possible explanation is the hypothesis that $S$ expects more than one item on a trial. Hinrichs (1973) has reported evidence from an experiment in which Ss gave two guesses before each trial. He found that the second guess would reduce RT when correct.

Third, and most serious, is the finding that the slopes for negative and positive items were not parallel. This was true even if the point $M=1$ was excluded $(M=1$ was subject to response probability effects). In fact, the ratio of negative to positive slopes appears to be about $2: 1$ for both expected and nonexpected stimuli. This slope ratio would be expected if Ss were terminating their scan when a match was found, rather than scanning exhaustively. It is clear that a version of Model 1 which assumes that the $\mathrm{S}$ terminated upon a match within the positive set would provide a better fit to our data. Such a model would still have difficulties explaining the effects of stimulus frequency for nonexpected items and would require one of the revisions already suggested. It is not obvious to us why our data indicate self-termination. The expectancy responses could perhaps have induced $\mathrm{S}$ to alter his scanning strategy.

In any event, even if self-terminating scanning was adopted by the Ss, the basic finding remains of a large expectancy effect that does not interact with set size or positivity-negativity. Thus, the assumption that expected items are faster because they are scanned earlier in the search process is not tenable. Were this true, no expectancy effect would have been found for negative items. In other words, even a self-terminating model must assume that the expectancy effect is not based in the scanning process.

Up to this point, we have not distinguished between the perceptual and response stages as the locus of the expectancy effect. We feel that there are two main sources of evidence pointing to the perceptual stage as the source of the effect. First, we found no bias toward the expected response class. That is, there was no interaction between expectancy and response class. Second, Miller and Pachella (1973) covaried stimulus probability and stimulus clarity. The interaction that resulted seems to imply that stimulus probability was acting upon the perceptual stage (since clarity certainly acts at this stage). Thus, we somewhat tentatively conclude that expectancy acts on the time to perceive and encode an item prior to scanning.

Our results suggest at least five experimental questions for future investigations. First, is the assumption of a one-element expectancy buffer appropriate? The $\mathrm{S}$ may be able to expect more than one item or he may fail to expect any item on some trials. Second, can expectancy account for serial position effects in a systematic fashion? Third, can the expectancy model account adequately for sequential effects? Fourth, will the scanning pattern change if the E controls the probability that the expected item will be presented as a target? For example, if there is always an $80 \%$ chance that the item he expects will be tested, the S may begin to scan in accordance with Model 2. Fifth, what are the temporal decay characteristics, if any, of the expectancy? For the expectancy model to predict the interaction of temporal effects with serial position curves, there must be some temporal change in the effect of expectancy.

In summary, we think we have made a strong case for 
the effects of expectancy in scanning and related RT tasks. A simple extension of Sternberg's model can handle much of the data in the literature, in particular, frequency effects. It is also likely that serial position effects can be handled by distributing expectancies appropriately across serial positions. Our experiment demonstrated a large expectancy effect, probably found in the encoding stage. However, a number of alterations of our basic model would be necessary to fit the details of the results. We do not necessarily argue that Sternberg's exhaustive serial model is always correct. Rather, we argue that expectancy must be given prime consideration, whatever scanning procedure the $\mathrm{S}$ is led to adopt.

\section{APPENDIX}

For each study we list below the calculated root mean square error equal to

$$
\left[\Sigma\left(E_{i}-O_{i}\right)^{2} / N\right]^{1 / 2}
$$

where $E_{i}$ is the expected latency in milliseconds, $O_{i}$ is the observed latency in milliseconds, and the sum is taken over all the points being fit.

\begin{tabular}{|c|c|c|c|}
\hline & \multicolumn{3}{|c|}{ Root Mean Square Error } \\
\hline & \multicolumn{2}{|c|}{ Model } & \multirow[b]{2}{*}{ Other } \\
\hline & 1 & 2 & \\
\hline $\begin{array}{l}\text { ternberg (1966, Experiment 1, } \\
\text { see Fig. 1) }\end{array}$ & 8.8 & 9.8 & \\
\hline $\begin{array}{l}\text { ternberg (1966, Experiment 2, } \\
\text { see Fig. 2) }\end{array}$ & 6.8 & 5.2 & \\
\hline $\begin{array}{l}\text { Kirsner (1971, LETTERS, see } \\
\text { Fig. 4) }\end{array}$ & & & 4.3 \\
\hline $\begin{array}{l}\text { Kirsner (1971, WORDS, see } \\
\text { Fig. 4) }\end{array}$ & & & 1.8 \\
\hline $\begin{array}{l}\text { 4ternberg (1969b, Experiment } \\
\text { 4, see Fig. 6) }\end{array}$ & 12.9 & 11.8 & \\
\hline $\begin{array}{l}\text { Theios, Smith, Haviland, } \\
\text { Traupmann, and Moy } \\
\text { (1973, see Table 1) }\end{array}$ & 13.1 & 14.1 & \\
\hline Theios (1973, see Fig. 7) & 8.9 & 8.0 & \\
\hline $\begin{array}{l}\text { Klatzky and Smith (1972, see } \\
\text { Fig. 8) }\end{array}$ & 11.5 & 14.3 & \\
\hline $\begin{array}{l}\text { Burrows and Okada (1972, } \\
\text { see Fig. 9) }\end{array}$ & 6.3 & 5.4 & \\
\hline $\begin{array}{l}\text { hiffrin and Schneider (1973, } \\
\text { see Fig. 12) }\end{array}$ & 18.6 & & \\
\hline $\begin{array}{l}\text { hiffrin and Schneider (1973, } \\
\text { see Table 3) }\end{array}$ & 27.7 & & \\
\hline
\end{tabular}

\section{REFERENCES}

Bernstein, I. H., \& Reese, C. Behavioral hypotheses and choice reaction time. Psychonomic Science, 1965, 3, 259-260.

Bracey, G. W. Two operations in character recognition: A partial replication. Perception \& Psychophysics, 1969, 6, 357-360.

Brainard, R. W., Irby, T. S., Fitts, P. M., \& Alluisi, E. A. Some variables influencing the rate of gain of information. Journal of Experimental Psychology, 1962, 63, 321-329.

Briggs, G, E., \& Swanson, J. M. Encoding, decoding, and central functions in human information processing. Journal of Experimental Psychology, 1970, 86, 296-308.

Burrows, D., \& Okada, R. Serial position effects in high-speed memory search. Perception \& Psychophysics, 1971, 10 305-308.

Burrows, D., \& Okada, R. Divided attention and high-speed memory search. Paper presented at the annual meeting of the Eastern Psychological Association, Boston, April 1972.

Clifton, C.. Jr., \& Birenbaum, S. Effects of serial position and delay of probe in a memory scan task. Journal of Experimental Psychology, 1970, 86, 69-76

Corballis, M. C. Serial order in recognition and recall. Journal of Experimental Psychology, 1967, 74, 99-105.

Donders, F, C. Over de snelheid van psychische processen. Onderzoekingen gedaan in het Physiologish Laboratorium der Utrechtsche Hoogeschool, 1868-1869, Tweede reeks, II, 92-120. Transl. by W. G. Koster. In W. G. Koster (Ed.) Attention and performance II. Amsterdam: North-Holland, 1969. Acta Psychologica, 1969, 30, 412-431.

Falmagne, J. C. Stochastic models for choice reaction time with applications to experimental results. Journal of Mathematical Psychology, 1965, 12, 77-124.

Hinrichs, J. V. Probability and expectancy in two-choice reaction time. Psychonomic Science, 1970, 21, 227-228.

Hinrichs, J. V. Expectancy in choice reaction time: Evidence for a self-terminating serial memory model. Paper presented at the Sixth Indiana Theoretical and Mathematical Psychology Conference, 1973.

Hinrichs, J. V., \& Craft, J. L. Verbal expectancy in two-choice reaction time. Journal of Experim ental Psychology, 1970, 85, 330-334.

Hinrichs, J. V. \& Craft, J. L. Stimulus and response factors in discrete choice reaction time. Journal of Experimental Psychology, 1971, 88, 367-371

Hinrichs, J. V., \& Krainz, P. L. Expectancy in choice reaction time: Anticipation of stimulus or response? Journal of Experimental Psychology, 1970, 85, 330-334.

Hyman, R. Stimulus information as a determinant of choice reaction time. Journal of Experimental Psychology, 1953, 45. $188-196$.

Kirsner, K. Naming latency facilitation: An analysis of the encoding component in recognition reaction time. Journal of Experimental Psychology, 1972, 95, 171-176.

Kirsner, K., \& Craik, F. I. M. Naming and decision processes in short-term recognition memory. Joumal of Experimental Psychology, 1971, 88, 149-157.

Klatzky, R. L., Juola, J. F. \& Atkinson, R, C. Test stimulus representation and experimental context effects in memory scanning. Journal of Experimental Psychology, 1971, 87, 281-288.

Klatzky, R. L., \& Smith, E. E. Stimulus expectancy and retrieval from short-term memory. Journal of Experimental Psychology, 1972, 94, 101-107.

Kornblum, S. Sequential effects in choice reaction time: A tutorial review. In S. Kornblum (Ed.), Attention and performance IV. New York: Academic Press, 1973.

Krueger, L. E. Effect of stimulus probability on two-choice reaction time. Journal of Experimental Psychology, 1970, 84, 377-379.

Miller, J. O., \& Pachella, R. G. The locus of effect of stimulus probability on memory scanning. Journal of Experimental Psychology, 1974, in press.

Murdock, B. B., Jr. A parallel-processing model for scanning Perception \& Psychophysics, 1971, 10, 289-291.

Nickerson, R. S. Binary-classification reaction time: A review of some studies of human information-processing capabilities. Psychonomic Monograph Supplements, 1972, 4(Whole No. 65), 275-318

Peeke, S. C., \& Stone, G. C. Sequential effects in two- and four-choice tasks. Journal of Experimental Psychology, 1972, 92, $111-116$.

Posner, M. I. Information reduction in the analysis of sequential tasks. Psychological R eview, 1964, 71, 491-504.

Simpson, P. J. High-speed memory scanning: Stability and generality. Journal of Experimental Psychology, 1972, 96 239-246.

Smith, M. C. The repetition effect and short-term memory. Journal of Experimental Psychology, 1968, 77, 435-439.

Sternberg, S. High speed scanning in human memory. Science $1966,153,652-654$

Sternberg, S. Two operations in character recognition: Some evidence from reaction time measurements. Perception \& Psychophysics, 1967, 2, 45-53.

Sternberg, S. Memory-scanning: Mental processes revealed by reaction-time experiments. American Scientist, 1969a, 57. 421-457.

Sternberg, $S$. The discovery of processing stages: Extensions of Donders' method. In W. G. Koster (Ed.), Attention and performance II. Amsterdam: North-Holland, 1969b.

Swanson, J. M., \& Briggs, G. E. Information processing as a function of speed versus accuracy. Journal of Experimental Psychology, 1969, 81, 223-229.

Theios, J. Reaction time measurements in the study of memory processes: Theory and data. In G. H. Bower (Ed.), The psychology of learning and motivation VII. New York: Academ ic Press, 1973. 
Theios, J., Smith, P, G., Haviland, S. E., Traupmann, J., \& Moy $M$. C. Memory scanning as a serial self-terminating process. Journal of Experimental Psychology, 1973, 97, 323-336.

\section{NOTES}

1. In a number of personal communications, Sternberg has affirmed this statement and suggested the possibility that the scan time during the comparison stage might vary from item to item, perhaps as a functinn of seral position (see also the discussion of Burrows \& Okada, 1971).

2. Theios (1973) presents similar data for a related experiment, but with a much smaller overall effect because se size of 1 was not used. For Kirsner's experiment, our predicted change from Set Size 2 to Set Size 8 was only $17 \mathrm{msec}$

3 . It was assumed that the $S$ expected only positive set items because (1) the positive set occurred on $60 \%$ of the trials, (2) the $S$ was given a bias on $5 / 6$ of the trials, and (3) the positive set was given to the $S$ before each trial.

4. In retrospect, it would have been advisable to use negative sets larger than positive sets, so that $S$ would always have a rational basis for placing the positive set in short-term store. However, we should point out that $S$ s in fact had a strong bias toward utilizing the set we designated as positive: Only this set was given to $S$; $S$ was not told the negative set was of the same size and did not know what were the members of the negative set, except as he learned them through experience during the block of trials; and finally, no Ss reported using the negative set except for the set size of 1 .

5. Different Ss may have perceived different pressures due to this payoff procedure. In any event, all $S$ s met the specified standards after the first three sessions.

6. The model predicts that the frequency effects normally seen result from mixing two distributions: one with a fast mean and one with a slow mean. Falmagne (1965) has pointed out that the resultant distributions should exhibit a "fixed-point" property. Unfortunately, the distributions were too noisy to permit a test of this property or of other predictions based on distributional analysis.

(Accepted March 2, 1974.) 